\title{
Computed Tomography Enterography Demonstrates Association to Histopathological Grading of Small Bowel Crohn's Activity
}

\author{
Husam H Mansour ${ }^{1,2 \star}$, Yasser S Alajerami ${ }^{2}$, Ahmed A Najim ${ }^{3}$, Khaled M Abushab ${ }^{2}$
}

${ }^{1}$ Radiology Department, Al-Shifa Hospital, Gaza, PALESTINE

${ }^{2}$ Medical Imaging Department, Al-Azhar University, Gaza, PALESTINE

${ }^{3}$ Nursing Department, Al-Azhar University, Gaza, PALESTINE

*Corresponding Author: husam-rt2007@hotmail.com

Citation: Mansour HH, Alajerami YS, Najim AA, Abushab KM. Computed Tomography Enterography Demonstrates Association to Histopathological Grading of Small Bowel Crohn's Activity. Electron J Gen Med. 2021;18(6):em330. https://doi.org/10.29333/ejgm/11317

ARTICLE INFO

Received: 26 Mar. 2021

Accepted: 7 Oct. 2021

\begin{abstract}
Introduction: Crohn's disease (CD) is a lifelong, progressive inflammatory condition of the bowel that adversely influences the quality of life. Diagnosis of $\mathrm{CD}$ can be challenging, as there is no trusted gold standard diagnostic procedure. lleocolonoscopy cannot investigate the entire small bowel due to small bowel morphology. Multislice Computed Tomography (MSCT) improves small bowel imaging and has established a crucial role for Computed Tomography Enterography (CTE).
\end{abstract}

Objective: This study investigated an association between CTE and histopathology in the evaluation of the activity of small bowel CD.

Materials and Methods: A retrospective study was used to collect eligible cases. The sample size was a consecutive sampling of 98 patients with known CD. The patients underwent biopsy by ileocolonoscopy-guided retrograde terminal ileum intubation. Subjects were scanned with CTE for confirmation of the diagnosis, detection of complications, and further evaluation of CD. A Chi-Square test was performed to determine the association between CTE radiological pathological findings and CTE grading.

Results: The peak prevalence of Crohn's activity occurred between the ages of 20-30 years. Definitive clinical presentations of $C D$ include diarrhea, abdominal pain, and weight loss, frequently followed by a chronic deteriorating progression, with distinct variations in the type and severity of symptoms. Fisher exact test showed that there is a statistically significant association between radiological pathological findings of CTE and CTE diagnostic grading of $C D(0.05,2$-sided). Moreover, there is a relationship between radiological pathological findings of CTE and histopathological findings.

Conclusions: The CTE radiological pathological findings demonstrate an association with the histopathological findings of $C D$. The CTE findings may be helpful for the differential diagnosis and planning of treatment strategy.

Keywords: computed tomography enterography, Crohn's disease, histopathology

\section{INTRODUCTION}

Crohn's disease (CD) is a chronic inflammatory disorder that affects different parts of the gastrointestinal tract, most commonly the small bowel [1]. The diagnosis of $C D$ is based on clinical data and radiological, endoscopic, and histopathological analysis [2]. Radiological procedures are an integral part of $C D$ diagnosis and monitoring, in coincidence with ileocolonoscopy ic investigations. Improved small bowe imaging with developments in Multislice Computed Tomography (MSCT) and use of neutral oral contrast has established a crucial role for Computed Tomography Enterography (CTE). This has resulted in a shift toward the use of CTE imaging versus fluoroscopic examination in the diagnosis and follow up of patients with CD. CTE exhibits high sensitivity for recognition of clinically undetectable $C D$ complications [3].
Comparison of CTE and Magnetic Resonance Enterography (MRE) has confirmed the similar performance of the two procedures for identifying active CD [4]. There is a good correlation among ileocolonoscopy, CTE and MRE findings [5]. The rapidity of the CTE procedure is its advantage over MRE. The short acquisition times of CTE create images free of motion artifacts, which are caused by normal intestinal peristalsis [6]. Accuracy in categorizing disease activity is critical for disease prognosis and evaluation of treatment effectiveness. lleocolonoscopy is the gold standard for diagnosing and assessing CD activity, but its aggressive nature and associated complications restrict the implementation in $C D$ for long-term patient follow-up. Consequently, CTE is commonly used in clinical practice [7]. Nevertheless, there are insufficient studies related to the grading of lesion activity and quantitative assessment of CTE imaging findings in CD patients [8].

CTE is readily accessible, fast, exhibits high spatial resolution, and is well tolerated by patients. CTE may be superior to MRE in terms of image quality and inter-observer 
Table 1. Cross-tabulation of histopathological grading of Crohn's activity versus gender

\begin{tabular}{|c|c|c|c|c|c|c|}
\hline \multirow{2}{*}{ Gender } & \multicolumn{3}{|c|}{ Histopathological analysis of Crohn's activity } & \multirow{2}{*}{$\begin{array}{c}\text { Total } \\
(n=98)\end{array}$} & \multirow{2}{*}{$\chi^{2}$} & \multirow{2}{*}{$P$-value } \\
\hline & Mild (n=18) & Moderate $(n=42)$ & Severe $(n=38)$ & & & \\
\hline Male & $16(88.9 \%)$ & $23(54.8 \%)$ & $14(36.8 \%)$ & $53(54.1 \%)$ & \multirow{2}{*}{13.902} & \multirow{2}{*}{$0.001^{*}$} \\
\hline Female & $2(11.1 \%)$ & $19(45.2 \%)$ & $24(63.2 \%)$ & $45(45.9 \%)$ & & \\
\hline
\end{tabular}

* Significant at 0.05 level of Fisher Exact significance (2-sided)

Table 2. Cross-tabulation of histopathological grading of Crohn's activity versus age group

\begin{tabular}{|c|c|c|c|c|c|c|}
\hline \multirow{2}{*}{ Age groups } & \multicolumn{3}{|c|}{ Histopathological analysis of Crohn's activity } & \multirow{2}{*}{$\begin{array}{c}\text { Total } \\
(n=98)\end{array}$} & \multirow{2}{*}{$\chi^{2}$} & \multirow{2}{*}{$P$-value } \\
\hline & Mild (n=18) & Moderate $(n=42)$ & Severe $(n=38)$ & & & \\
\hline Less than $20 y$ & $2(11.1 \%)$ & $7(16.7 \%)$ & $0(0)$ & $9(9.2 \%)$ & \multirow{5}{*}{46.836} & \multirow{5}{*}{$<0.001^{\star}$} \\
\hline $20 y$ to $30 y$ & $13(72.2 \%)$ & $24(57.1 \%)$ & $7(18.4 \%)$ & $44(44.9 \%)$ & & \\
\hline $31 y$ to $40 y$ & $3(16.7 \%)$ & $9(21.4 \%)$ & $8(21.1 \%)$ & $20(20.4 \%)$ & & \\
\hline $41 y$ to $50 y$ & $0(0)$ & $2(4.8 \%)$ & $9(23.7 \%)$ & $11(11.2 \%)$ & & \\
\hline More than 51y & $0(0)$ & $0(0)$ & $14(36.8 \%)$ & $14(14.3 \%)$ & & \\
\hline
\end{tabular}

agreement. Nowadays, there are several strategies available to reduce radiation dose exposure with no compromise of diagnostic accuracy. Nevertheless, cumulative radiation exposure of $C D$ patients undergoing repeated $C T E$ needs to be carefully considering. The current study explored the viability of CTE in quantitatively assessing and grading CD activity relative to the histopathological results of ileocolonoscopic biopsies.

\section{MATERIALS AND METHODS}

\section{Study Design and Participants}

We performed a retrospective study among 98 patients with known or suspected CD, in which CTE was performed to evaluate its possible impact on accurate diagnosis, detection of complications, and consequent guidance for management. The data were collected from the medical records of 98 consecutive patients who had been referred to a gastroenterologist for small bowel evaluation and who underwent biopsy by ileocolonoscopy retrograde terminal ileum intubation. These patients underwented CTE to confirm the diagnosis and for further evaluation of the disease. The study excluded all patients who had suboptimal CTE or ileocolonoscopy and patients who had incomplete medical records.

\section{Protocol for CTE}

CTE studies were performed using a 64-slice Siemens SOMATOM Definition AS. Patients abstained from food for at least six hours before the CTE examination without any other bowel preparation. They were instructed to drink $1350 \mathrm{ml}$ of a neutral oral contrast medium solution comprised of Mannitol diluted with water $(20 \%)$ to obtain good distension of the small bowel. The solution was ingested as follows: $450 \mathrm{ml}$ at 60 minutes; $450 \mathrm{ml}$ at 40 minutes; $225 \mathrm{ml}$ at 20 minutes; and 225 $\mathrm{ml}$ at 10 minutes before scanning. An 18-gauge cannula intravenous line was placed in the antecubital fossa.

A dose of $80-100 \mathrm{ml}$ lohexol injection, a high-iodine concentration contrast agent (OMNIPAQUE 350 contains 755 $\mathrm{mg}$ of lohexol equivalent to $350 \mathrm{mg}$ of organic iodine per $\mathrm{ml}, \mathrm{GE}$ Healthcare) was injected at a flow rate of $4 \mathrm{ml} / \mathrm{s}$ followed by a $40-\mathrm{ml}$ bolus of saline at the same flow rate.

With the patient supine on the examination table, scout images were obtained from the diaphragm superiorly down to the symphysis pubis inferiorly. Enteric phase images were obtained at 45-50s after initiation of IV contrast. All imaging was performed with $120-140 \mathrm{kV}, 200-350 \mathrm{~mA}$, matrix $512 \times 512$, pitch $0.8-1$ and slice collimation $1.25 \mathrm{~mm}$. Axial and coronal images were reconstructed at a slice thickness of $2 \mathrm{~mm}$ and an increment of $2 \mathrm{~mm}$ using a B20 medium smooth kernel.

\section{Statistical Analysis}

IBM SPSS Statistic Version 23.0 (IBM Corporation, New York, USA) was used for data entry and analysis. Several correlations were used to describe the relationships among demographic characteristics, clinical manifestations, and CTE radiological pathological findings versus histopathological grading. $P<0.05$ was considered to be significant.

\section{RESULTS}

\section{Baseline Characteristics}

The study included 53 (54.1\%) males and 45 (45.9\%) females (Table 1). The Fisher exact test of independence was used for frequencies of fewer than five observations. This test revealed that gender had a significant influence on the histopathological grading of Crohn's activity (Fisher exact test $=13.902$ and $\mathrm{P}=0.001$ ).

The degree of Crohn's activity among patients was inconsistent. Histopathological analysis of specimens obtained from bowel wall tissues taken through ileocolonoscopy biopsies revealed mild Crohn's activity in 16 $(88.9 \%)$ male patients versus two $(11.1 \%)$ female patients. Moderate CD was found in 23 (54.8\%) males versus 19 (45.2\%) females, and severe CD was found in $14(36.8 \%)$ males versus $24(63.2 \%)$ females.

Age prevalence of Crohn's activity in patients with histopathological grading is listed in Table 2. Peak prevalence of Crohn's activity by age group was evident, with the peak occurring between the ages of 20-30 years. Furthermore, the Fisher exact test reveals that the patients' age has a significant incidence of the histopathological grading of Crohn's activity, where the value of the Fisher exact test was 46.836 and $P$ $<0.001$.

\section{Clinical Manifestations of CD Patients}

The main clinical manifestations of CD patients related to the degree of Crohn's activity are presented in Table 3 . The 
Table 3. Cross-tabulation of histopathological grading of Crohn's activity versus clinical manifestations

\begin{tabular}{|c|c|c|c|c|c|c|c|}
\hline \multirow{2}{*}{\multicolumn{2}{|c|}{ Clinical manifestations of CD patients }} & \multicolumn{3}{|c|}{ Histopathological grading of Crohn's activity } & \multirow{2}{*}{$\begin{array}{c}\text { Total } \\
(n=98)\end{array}$} & \multirow{2}{*}{$\chi^{2}$} & \multirow{2}{*}{$P$-value } \\
\hline & & Mild ( $n=18)$ & Moderate $(n=42)$ & Severe $(n=38)$ & & & \\
\hline \multirow{2}{*}{ Abdominal pain } & Yes & $13(72.2 \%)$ & $39(92.9 \%)$ & $36(94.7 \%)$ & $88(89.8 \%)$ & \multirow{2}{*}{6.046} & \multirow{2}{*}{$0.036^{\star}$} \\
\hline & No & $5(27.8 \%)$ & $3(7.1 \%)$ & $2(5.3 \%)$ & $10(10.2 \%)$ & & \\
\hline \multirow{2}{*}{ Diarrhea } & Yes & $16(88.9 \%)$ & $28(66.7 \%)$ & $36(94.7 \%)$ & $80(81.6 \%)$ & \multirow{2}{*}{10.826} & \multirow{2}{*}{$0.003^{\star}$} \\
\hline & No & $2(11.1 \%)$ & $14(33.3 \%)$ & $2(5.3 \%)$ & $18(18.4 \%)$ & & \\
\hline \multirow{2}{*}{ Hematochezia } & Yes & $9(50.0 \%)$ & $27(64.3 \%)$ & $35(92.1 \%)$ & $71(72.4 \%)$ & \multirow{2}{*}{14.132} & \multirow{2}{*}{$0.001^{\star}$} \\
\hline & No & $9(50.0 \%)$ & $15(35.7 \%)$ & $3(7.9 \%)$ & $27(27.6 \%)$ & & \\
\hline \multirow{2}{*}{ Weight loss } & Yes & $13(72.2 \%)$ & $23(54.8 \%)$ & $34(89.5 \%)$ & $70(71.4 \%)$ & \multirow{2}{*}{12.062} & \multirow{2}{*}{$0.002^{\star}$} \\
\hline & No & $5(27.8 \%)$ & $19(45.2 \%)$ & $4(10.5 \%)$ & $28(28.6 \%)$ & & \\
\hline
\end{tabular}

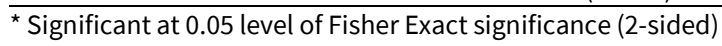

Table 4. Association between CTE radiological pathological findings and CTE grading

\begin{tabular}{|c|c|c|c|c|c|c|c|c|}
\hline \multirow{4}{*}{$\begin{array}{c}\text { CTE radiological } \\
\text { pathological } \\
\text { findings }\end{array}$} & \multicolumn{5}{|c|}{ CTE diagnosis grading of CD } & \multirow[b]{2}{*}{$\begin{array}{c}\text { Total } \\
(n=98)\end{array}$} & \multirow[b]{2}{*}{$\chi^{2}$} & \multirow[b]{2}{*}{$P$-value } \\
\hline & \multicolumn{2}{|c|}{$\begin{array}{c}\text { Absence } \\
(n=6)\end{array}$} & \multirow{3}{*}{$\begin{array}{c}\text { Mild }(\mathbf{n = 1 2}) \\
1(8.3 \%) \\
11(91.7 \%)\end{array}$} & \multirow{3}{*}{$\begin{array}{c}\text { Moderate }(\mathbf{n}=\mathbf{4 4}) \\
42(95.5 \%) \\
2(4.5 \%)\end{array}$} & \multirow{2}{*}{$\begin{array}{c}\text { Severe }(\mathbf{n = 3 6}) \\
16(44.4 \%)\end{array}$} & & & \\
\hline & Yes & $0(0)$ & & & & $59(60.2 \%)$ & \multirow{2}{*}{54.362} & \multirow{2}{*}{$<0.001^{\star}$} \\
\hline & No & $6(100 \%)$ & & & $20(55.6 \%)$ & $39(39.8 \%)$ & & \\
\hline \multirow{2}{*}{$\begin{array}{c}\text { Mucosal } \\
\text { hyperenhancement }\end{array}$} & Yes & $4(66.7 \%)$ & $12(100 \%)$ & $44(100 \%)$ & $36(100 \%)$ & $96(98.0 \%)$ & \multirow{2}{*}{10.681} & \multirow{2}{*}{$0.003^{\star}$} \\
\hline & No & $2(33.3 \%)$ & $0(0)$ & $0(0)$ & $0(0)$ & $2(2.0 \%)$ & & \\
\hline \multirow{2}{*}{$\begin{array}{c}\text { Intestinal wall } \\
\text { thickening }\end{array}$} & Yes & $0(0)$ & $0(0)$ & $0(0)$ & $28(77.8 \%)$ & $28(28.6 \%)$ & \multirow{2}{*}{70.165} & \multirow{2}{*}{$<0.001^{\star}$} \\
\hline & No & $6(100 \%)$ & $12(100 \%)$ & $44(100 \%)$ & $8(22.2 \%)$ & $70(71.4 \%)$ & & \\
\hline \multirow{2}{*}{$\begin{array}{c}\text { Engorgement of } \\
\text { mesenteric vessels }\end{array}$} & Yes & $0(0)$ & $0(0)$ & $0(0)$ & $21(58.3 \%)$ & $21(21.4 \%)$ & \multirow{2}{*}{45.079} & \multirow{2}{*}{$<0.001^{\star}$} \\
\hline & No & $6(100 \%)$ & $12(100 \%)$ & $44(100 \%)$ & $15(41.7 \%)$ & $77(78.6 \%)$ & & \\
\hline \multirow{2}{*}{$\begin{array}{l}\text { Free fluid adjacent } \\
\text { to the affected loop }\end{array}$} & Yes & $0(0)$ & $3(25.0 \%)$ & $11(25.0 \%)$ & $20(55.6 \%)$ & $34(34.7 \%)$ & \multirow{2}{*}{ 11. 728} & \multirow{2}{*}{$0.006^{\star}$} \\
\hline & No & $6(100 \%)$ & $9(75.0 \%)$ & $33(75.0 \%)$ & $16(44.4 \%)$ & $64(65.3 \%)$ & & \\
\hline \multirow{2}{*}{ Inter loop fistulas } & Yes & $0(0)$ & $0(0)$ & $0(0)$ & $10(27.8 \%)$ & $10(10.2 \%)$ & \multirow{2}{*}{16.431} & \multirow{2}{*}{$<0.001^{\star}$} \\
\hline & No & $6(100 \%)$ & $12(100 \%)$ & $44(100 \%)$ & $26(72.2 \%)$ & $88(89.8 \%)$ & & \\
\hline \multirow{2}{*}{$\begin{array}{c}\text { Enlarged } \\
\text { lymph nodes }\end{array}$} & Yes & $0(0)$ & $1(8.3 \%)$ & $9(20.5 \%)$ & $29(80.6 \%)$ & $39(39.8 \%)$ & \multirow{2}{*}{40.857} & \multirow{2}{*}{$<0.001^{\star}$} \\
\hline & No & $6(100 \%)$ & $11(91.7 \%)$ & $35(79.5 \%)$ & $7(19.4 \%)$ & $59(60.2 \%)$ & & \\
\hline \multirow{2}{*}{$\begin{array}{c}\text { Fat } \\
\text { abnormalities }\end{array}$} & Yes & $0(0)$ & $1(8.3 \%)$ & $29(65.9 \%)$ & $32(88.9 \%)$ & $62(63.3 \%)$ & \multirow{2}{*}{36.452} & \multirow{2}{*}{$<0.001^{\star}$} \\
\hline & No & $6(100 \%)$ & $11(91.7 \%)$ & $15(34.1 \%)$ & $4(11.1 \%)$ & $36(36.7 \%)$ & & \\
\hline \multirow{2}{*}{$\begin{array}{l}\text { Abscesses } \\
\text { formation }\end{array}$} & Yes & $0(0)$ & $0(0)$ & $0(0)$ & $8(22.2 \%)$ & $8(8.2 \%)$ & \multirow{2}{*}{12.312} & \\
\hline & No & $6(100 \%)$ & $12(100 \%)$ & $44(100 \%)$ & $28(77.8 \%)$ & $90(91.8 \%)$ & & 0.0 \\
\hline Intestinal & Yes & $0(0)$ & $0(0)$ & $0(0)$ & $14(38.9 \%)$ & $14(14.3 \%)$ & & \\
\hline Stricture & No & $6(100 \%)$ & $12(100 \%)$ & $44(100 \%)$ & $22(61.1 \%)$ & $84(85.7 \%)$ & 25.600 & \\
\hline
\end{tabular}

* Significant at 0.05 level of Fisher Exact Test (2-sided)

Fisher exact test revealed that abdominal pain, diarrhea, hematochezia, and weight loss were statistically significantly correlated with Crohn's activity. Abdominal pain was the most common clinical manifestation of Crohn's activity, with 88 $(89.8 \%)$ of the study patients suffering from abdominal pain (Fisher exact test $=6.046$ and $P=0.036$ ). Diarrhea was a second common clinical manifestation of Crohn's activity, with 80 $(81.6 \%)$ of the patients suffering from diarrhea (Fisher exact test $=10.826$ and $\mathrm{P}=0.003$ ). Hematochezia was prominent in 71 $(72.4 \%)$ of the study patients (Fisher exact test $=14.132$ and $\mathrm{P}=$ 0.001). Weight loss was documented in $70(71.4 \%)$ patients (Fisher exact test $=12.062$ and $P=0.002$ ).

\section{Radiological Pathological Findings of CTE Associated with CTE Diagnosis Grading of Crohn's Activity}

To explore the relationship between radiological pathological findings of CTE and CTE diagnostic grading of Crohn's activity, the Fisher exact test was used to find the relationship between these two qualitative variables. The results in Table 4 show that there is an association between radiological pathological findings of CTE and CTE diagnostic grading of $C D$ at the 0.05 level of significance (2-sided).

Regarding CTE image interpretation, mucosal hyperenhancement was observed in the majority of $C D$ patients (98.0\%) (Fisher exact test $=10.681$ and $P=0.003$ ). Mucosal hyper-enhancement was observed in all degrees (mild, moderate, and severe) of $C D$, while images from two-thirds of patients who classified without CD were interpreted with mucosal hyper-enhancement.

The next common findings were fat abnormalities in 62 patients (63.3\%) (Fisher exact test $=36.452$ and $P<0.001)$. Fat abnormalities were prominent in 32 patients (88.9\%) with severe $C D$, followed with 29 patients (65.9\%) with moderate $C D$ and only one $(8.3 \%)$ with mild CD. Mucosal vascularity was a common finding in 59 patients (60.2\%) (Fisher exact test $=$ 54.362 and $P<0.001)$. Among patients with moderate $C D$, about 42 cases $(95.5 \%)$ had mucosal vascularity, whereas this was observed in 16 severe CD patients (44.4\%) and only one mild CD patient (8.3\%).

Enlarged lymph nodes were observed in 39 patients (39.8\%) (Fisher exact test $=40.857$ and $\mathrm{P}<0.001)$. Enlarged nodes were evident in 29 of severe CD patients $(80.6 \%)$, in nine of the moderate cases $(20.5 \%)$ and only one $(8.3 \%)$ of the mild patients. Free fluid adjacent to the affected loop was seen in 34 patients (34.7\%) (Fisher exact test $=11.728$ and $P=0.006), 20$ of whom with severe CD (55.6\%), 7 with moderate, and 7 with mild CD.

The remaining radiological pathological findings of CTE were certain for severe CD patients. Intestinal wall thickening existing in $28 \mathrm{CD}$ patients (28.2\%) (Fisher exact test $=70.165$ and $\mathrm{P}<0.001$ ). These patients represent about $77.8 \%$ of the 
Table 5. Association between CTE radiological findings and histopathological analysis grading.

\begin{tabular}{|c|c|c|c|c|c|c|c|}
\hline \multirow{2}{*}{\multicolumn{2}{|c|}{ CTE radiological pathological findings }} & \multicolumn{3}{|c|}{ Histopathological analysis of CD grading } & \multirow{2}{*}{$\begin{array}{c}\text { Total } \\
(n=98)\end{array}$} & \multirow{2}{*}{$\chi^{2}$} & \multirow{2}{*}{$P$-value } \\
\hline & & Mild $(n=18)$ & Moderate $(n=42)$ & Severe $(n=38)$ & & & \\
\hline \multirow{2}{*}{$\begin{array}{c}\text { Mucosal } \\
\text { vascularity }\end{array}$} & Yes & $1(5.6 \%)$ & $35(83.3 \%)$ & $23(60.5 \%)$ & $59(60.2 \%)$ & \multirow{2}{*}{33.322} & \multirow{2}{*}{$<0.001^{\star}$} \\
\hline & No & $17(94.4 \%)$ & $7(16.7 \%)$ & $15(39.5 \%)$ & $39(39.8 \%)$ & & \\
\hline \multirow{2}{*}{$\begin{array}{c}\text { Mucosal } \\
\text { hyperenhancement }\end{array}$} & Yes & $16(88.9 \%)$ & $42(100.0 \%)$ & $38(100.0 \%)$ & $96(98.0 \%)$ & \multirow{2}{*}{5.341} & \multirow{2}{*}{$0.032^{\star}$} \\
\hline & No & $2(11.1 \%)$ & $0(0)$ & $0(0)$ & $2(2.0 \%)$ & & \\
\hline \multirow{2}{*}{$\begin{array}{c}\text { Intestinal } \\
\text { wall thickening }\end{array}$} & Yes & $0(0)$ & $0(0)$ & $28(73.7 \%)$ & $28(28.6 \%)$ & \multirow{2}{*}{66.295} & \multirow{2}{*}{$<0.001^{\star}$} \\
\hline & No & $18(100 \%)$ & $42(100.0 \%)$ & $10(26.3 \%)$ & $70(71.4 \%)$ & & \\
\hline \multirow{2}{*}{$\begin{array}{c}\text { Engorgement of } \\
\text { mesenteric vessels }\end{array}$} & Yes & $0(0)$ & $0(0)$ & $21(55.3 \%)$ & $21(21.4 \%)$ & \multirow{2}{*}{43.229} & \multirow{2}{*}{$<0.001^{\star}$} \\
\hline & No & $18(100 \%)$ & $42(100.0 \%)$ & $17(44.7 \%)$ & $77(78.6 \%)$ & & \\
\hline \multirow{2}{*}{$\begin{array}{l}\text { Free fluid adjacent } \\
\text { to the affected loop }\end{array}$} & Yes & $3(16.7 \%)$ & $8(19.0 \%)$ & $23(60.5 \%)$ & $34(34.7 \%)$ & \multirow{2}{*}{17.687} & \multirow{2}{*}{$<0.001^{\star}$} \\
\hline & No & $15(83.3 \%)$ & $34(81.0 \%)$ & $15(39.5 \%)$ & $64(65.3 \%)$ & & \\
\hline \multirow{2}{*}{$\begin{array}{c}\text { Inter loop } \\
\text { fistulas }\end{array}$} & Yes & $0(0)$ & $0(0)$ & $10(26.3 \%)$ & $10(10.2 \%)$ & \multirow{2}{*}{16.016} & \multirow{2}{*}{$<0.001^{\star}$} \\
\hline & No & $18(100 \%)$ & $42(100.0 \%)$ & $28(73.7 \%)$ & $88(89.8 \%)$ & & \\
\hline \multirow{2}{*}{$\begin{array}{c}\text { Enlarged } \\
\text { lymph nodes }\end{array}$} & Yes & $1(5.6 \%)$ & $13(31.0 \%)$ & $25(65.8 \%)$ & $39(39.8 \%)$ & \multirow{2}{*}{21.717} & \multirow{2}{*}{$<0.001^{\star}$} \\
\hline & No & $17(94.4 \%)$ & $29(69.0 \%)$ & $13(34.2 \%)$ & $59(60.2 \%)$ & & \\
\hline \multirow{2}{*}{$\begin{array}{c}\text { Fat } \\
\text { abnormalities }\end{array}$} & Yes & $1(5.6 \%)$ & $27(64.3 \%)$ & $34(89.5 \%)$ & $62(63.3 \%)$ & \multirow{2}{*}{38.639} & \multirow{2}{*}{$<0.001^{\star}$} \\
\hline & No & $17(94.4 \%)$ & $15(35.7 \%)$ & $4(10.5 \%)$ & $36(36.7 \%)$ & & \\
\hline \multirow{2}{*}{$\begin{array}{l}\text { Abscesses } \\
\text { formation }\end{array}$} & Yes & $0(0)$ & $0(0)$ & $8(21.1 \%)$ & $8(8.2 \%)$ & \multirow{2}{*}{11.978} & \multirow{2}{*}{$0.001^{\star}$} \\
\hline & No & $18(100 \%)$ & $42(100.0 \%)$ & $30(78.9 \%)$ & $90(91.8 \%)$ & & \\
\hline \multirow{2}{*}{$\begin{array}{l}\text { Intestinal } \\
\text { Stricture }\end{array}$} & Yes & $0(0)$ & $1(2.4 \%)$ & $13(34.2 \%)$ & $14(14.3 \%)$ & \multirow{2}{*}{18.591} & \\
\hline & No & $18(100 \%)$ & $41(97.6 \%)$ & $25(65.8 \%)$ & $84(85.7 \%)$ & & $<0.001^{\star}$ \\
\hline
\end{tabular}

* Significant at 0.05 level of Fisher Exact significance (2-sided)

severe $C D$ group. Engorgement of mesenteric vessels was seen in 21 patients $(21.4 \%)$ (Fisher exact test $=45.079$ and $P<0.001$ ), which represent about $58.3 \%$ of the severe group. Disease complications were classified into intestinal stricture, inter loop fistulas, and abscess formation. Intestinal stricture was evident in 14 patients (14.3\%) (Fisher exact test $=25.660$ and $\mathrm{P}$ $<0.001$ ) representing $38.9 \%$ of severe cases. Inter loop fistulas were seen in $10(10.2 \%)$ CD patients (Fisher exact test $=25.660$ and $P<0.001)$ representing $27.8 \%$ of the severe subjects. Abscess formation was seen in 8 patients (8.2\%) (Fisher exact test $=12.312$ and $\mathrm{P}=0.002$ ) representing $22.2 \%$ of the severe group.

\section{Radiological Pathological Findings of CTE Associated with Histopathological Diagnostic Grading of Crohn's Activity}

To test the relationship between radiological pathological findings of CTE and grading based on histopathological analysis, the 2-sided Fisher exact test was used. The results presented in Table 5 show that there is a relationship between radiological pathological findings of CTE and histopathological findings at the 0.05 level of significance. Thus, all CTE radiological pathological findings are good predictors of histopathological findings relevant to $C D$.

\section{DISCUSSION}

In agreement with our results, Costea et al. [9] reported that the gender distribution of $C D$ is about $56.4 \%$ male and $43.6 \%$ female. In general, the frequency of $C D$ is similar in males and females. This pattern is reversed with pediatric $C D$, which has a higher incidence in pediatric males than in females [10].

Age descriptions of early and elderly onset $C D$ within the literature diverge and frequently depend on clinical practice due to the age of referral from pediatric to adult CD care. Besides, a dilemma in patient characteristics, diagnostic criteria, access to diagnostic modalities, and hence variation in the ability to capture altogether CD patients might bias and confound associations. Specific studies indicated that elderly patients were more likely to have a colonic disease and less likely to have ileocolonic $C D$ when matched with the younger age groups [11,12]. In accord with our results, European reports have shown an increasing prevalence of $C D$ in the age group 20 to 30 years $[13,14]$. Furthermore, similar studies confirm that the vast majority of patients with $C D$ are frequently diagnosed in the same age group $[15,16]$.

The clinical manifestations of $C D$ are important in the investigation of $C D$ patients in that they can predict $C D$ activity. Sands [17] reported that diarrhea is the most common presenting symptom of $C D$. According to Jaffe et al. [18], the definitive clinical presentation of $C D$ is abdominal pain, weight loss, and diarrhea. Clinical signs and symptoms of patients with CD are essentially correlated with diagnostic modalities as well as laboratory test results [19]. Dos Santos et al. [20] reported the clinical manifestations of CTE and revealed that the main clinical manifestations were abdominal pain (85\%), diarrhea (70\%), weight loss (64\%), and hematochezia (55\%).

Interpretation of CTE images with attention to the radiological pathological findings of $C D$ is essential to judgment of Crohn's activity grading. Radiological pathological findings such as mucosal hyper-enhancement, intestinal wall thickening, fat abnormalities, and extraintestinal features are consistent with active small bowel CD [21]. A study done by Choi et al. [22] revealed that mucosal hyper-enhancement and intestinal wall thickening were predictive of active $C D$. Intestinal wall thickening in CD refers to a wall thickness of greater than $3 \mathrm{~mm}$ under conditions of an optimal CTE procedure with a good distended bowel loop [23]. Intestinal wall thickening is the most frequent finding observed with CTE for CD patients (up to $82 \%$ of patients) [24].

Among these radiological pathological observables, a combination of mucosal hyper-enhancement and intestinal wall thickening is the most sensitive CTE finding signifying active inflammatory $C D[6,25]$. While these studies suggested that intestinal wall thickening correlated best with Crohn's activity, another study has suggested that mucosal hyperenhancement may be an extra sensitive sign [26]. The comb sign refers to engorged vasa recta that infiltrate the bowel wall 
perpendicular to the bowel lumen, suggesting the appearance of a comb [24]. Mesenteric fat abnormalities together with the comb sign were reported to be the most specific CTE finding for active CD [27]. Chiorean et al. [28] identified that CTE findings of comb sign and enlarged mesenteric lymph nodes were strongly correlated with Crohn's activity.

Extra-enteric complications of CD are accurately identified by CTE. The most common of these complications include inter loop fistulas and abscess formation [29]. Variability of Crohn's activity assessed by CTE radiological pathological findings is reliant on whether the activity is a result of acute or chronic inflammation and whether there are complications such as inter loop fistulas, intestinal stricture, or abscess formation. In a study of CD patients who underwent CTE and ileocolonoscopy, mucosal hyper-enhancement and intestinal wall thickening on CTE correlated highly significantly ( $P=$ 0.001) with histopathological findings of active CD [30].

Concerning our results, preliminary studies suggested that mucosal hyper-enhancement, intestinal wall thickening, enlarged mesenteric lymph nodes were correlated significantly with histopathological findings of active CD [21,26,31]. A study by Patel et al. [32] explored the radiological findings correlated to clinical manifestation and ileocolonoscopy appearances. They reported that intestinal wall thickening and mucosal hyper-enhancement showed a positive correlation with clinical severity $(P<0.05)$ and identified a statistically significant correlation with ileocolonoscopy severity $(P<0.0001)$.

A comparative study carried out by Hashimoto et al. [33] compared CTE radiological findings of CD patients with a different diagnostic approach. Their study revealed a strong correlation $(P<0.001)$ between CTE radiological findings and mucosal surface. In particular, CTE appeared to be a valuable diagnostic technique for the assessment of the mucosal healing pattern in CD.

Park and Lim [34] reported that extra-enteric complications of $C D$ are distinguished by CTE. The accurate detection of abscesses and inter loop fistulas have high significance not only because it alters the disease management decision but also can affect the surgical approach. Peng et al. [35] investigated the accuracy of new spectral CT generation in assessment Crohn's activity in comparison to conventional CT. The results showed that bowel wall hyper-enhancement, on comb sign, intestinal wall thickness, and normalized iodine concentration increased significantly $(P<0.01)$ with ileocolonoscopy severity.

In concordance with our results, a recent study by Cheng et al. [8] explored the viability of CTE in the quantitative evaluation of $C D$ activity. They reported that intestinal stricture among active mild, moderate, and severe groups was statistically significant (Chi-square test $=13.3$ and $P<0.001$ ). Similarly, mesenteric hyper-vascularity (comb sign) was statistically significant (Chi-square test $=9.3$ and $P=0.005$ ). The difference in mucosal enhancement among inactive, mild, moderate and severe groups was significantly different in patients without $C D$ activity and the mild groups (Chi-square test $=15.7$ and $P=0.001$ ). The difference between the group showing no $C D$ activity and moderate-severe groups was statistically significant (Chi-square test $=14.1$ and $P=0.003$ ). Moreover, the supplementary comparison showed that wall thickening was statistically significant $(P=0002)$ between the absent $C D$ activity and the mild groups, and statistically significant $(P<0.001)$ between the inactive and the moderatesevere groups.
In this context, despite extensive availability in clinical practice, the performance of CTE relative to ileocolonoscopy as a diagnostic method as well as measures to evaluate treatment response in $C D$ are important subjects to be investigated. Our results agree with a recent prospective study [36] designed to evaluate the correlation between CTE pathological findings and ileocolonoscopy disease activity. That study revealed that CTE findings significantly correlated with those of ileocolonoscopy. Ileocolonoscopy at one year follow up significantly correlated with improvement in mucosal hyperenhancement $(P=0.004)$, mesenteric fat abnormality $(P=$ $0.001)$, comb sign $(P=0.004)$, and inter loop strictures $(P=$ 0.008) in CTE.

\section{CONCLUSION}

Demonstration of radiological pathological features of CD in CTE images is crucial to determine Crohn's activity grading. These features are reliable predictors that support the histopathological features of CD. The current study highlights CTE's capability to assess the presence, severity, and extent of $\mathrm{CD}$ and its complications that is not available from clinical and ilicolonoscopic evaluation. Furthemore, our study establishes a common expectation for the use of CTE in patients with small bowel CD, as well as agreed-upon radiological imaging findings. Finally, the study suggests that CTE would be the method of choice for follow up, preoperative guidance in the planning of a treatment strategy, and monitoring the patient response to treatment.

Author contributions: All authors participated in idea formation, data gathering, data analysis and interpretation, manuscript drafting and revising. All contributors approved the manuscript and agreed with study publication.

Funding: This research received no specific grant from any funding agency in the public, commercial, or not-for-profit sectors.

Acknowledgements: The authors wish to thank Prof. Thomas Foster of the University of Rochester, Rochester, NY USA for his careful reading of the manuscript, helpful suggestions, and English language editing.

Ethical statement: Ethical approval for this study was obtained from the Helsinki Committee, Gaza strip, Palestine.

Declaration of interest: The authors declared no conflict of interest concerning the research, authorship, and publication of this article.

\section{REFERENCES}

1. Thia K, Sandborn W, Harmsen W, Zinsmeister A, Loftus EV. (2010) Risk factors associated with progression to intestinal complications of Crohn's disease in a population-based cohort. Gastroenterology 2010;139(4):1147-55. https://doi.org/10.1053/j.gastro.2010.06.070

PMid:20637205 PMCid:PMC2950117

2. Maaser C, Sturm A, Vavricka SR, et al. ECCO-ESGAR guideline for diagnostic assessment in IBD Part 1: Initial diagnosis, monitoring of known IBD, detection of complications. J. Crohn's Colitis 2018;13(2):144-64. https://doi.org/10.1093/ecco-jcc/jjy113 PMid:30137275

3. Kim SH. Computed tomography enterography and magnetic resonance enterography in the diagnosis of Crohn's disease. Intest. Res. 2015;13(1):27-38. https://doi.org/10.5217/ir.2015.13.1.27

PMCid:PMC4316219 
4. Heverhagen JT. Invited commentary on "Small bowel Crohn disease at CT and MR Enterography," with response from Dr Guglielmo et al. RadioGraphics 2020;40(2):375-377. https://doi.org/10.1148/rg.2020190213 PMid:32125960

5. Liu W, Liu J, Xiao W, Luo G. A Diagnostic Accuracy Metaanalysis of CT and MRI for the evaluation of small bowel Crohn disease. Acad. Radiol. 2017;24(10):1216-25. https://doi.org/10.1016/j.acra.2017.04.013 PMid:28595876

6. Booya F, Fletcher JG, Huprich JE, et al. Active Crohn disease: CT findings and interobserver agreement for enteric phase CT enterography. Radiology 2006;241(3):78795. https://doi.org/10.1148/radiol.2413051444 PMid: 17032911

7. Daperno M, D'Haens G, Van Assche G, et al. Development and validation of a new, simplified endoscopic activity score for Crohn's disease: the SES-CD. Gastrointest Endosc. 2004;60(4):505-12.

https://doi.org/10.1016/s00165107(04)01878-4

8. Cheng J, Xie H, Yang H, Wang K, Xu G, Wu G. Computed Tomography Enterography: Quantitative Evaluation on Crohn's Disease Activity. Gastroenterol Res Pract. 2018;2018:1-6. https://doi.org/10.1155/2018/7351936 PMid:30140280 PMCid:PMC6081582

9. Costea I, Mack DR, Israel D, et al. Genes involved in the metabolism of Poly-Unsaturated Fatty-Acids (PUFA) and risk for Crohn's disease in children \& young adults. PLoS One. 2010;5(12):e15672. https://doi.org/10.1371/journal. pone.0015672 PMid:21187935 PMCid:PMC3004960

10. Matsuoka K, Kobayashi T, Ueno F, et al. Evidence-based clinical practice guidelines for inflammatory bowel disease. J Gastroenterol. 2018;53(3):305-53. https://doi.org/10.1007 /s00535-018-1439-1 PMid:29429045 PMCid:PMC5847182

11. Gower-Rousseau C, Vasseur F, Fumery M, et al. Epidemiology of inflammatory bowel diseases: New insights from a French population-based registry (EPIMAD). Dig Liver Dis. 2013;45(2):89-94. https://doi.org/10.1016/ j.dld.2012.09.005 PMid:23107487

12. Stepaniuk P, Bernstein CN, Targownik LE, Singh $H$. Characterization of Inflammatory Bowel Disease in Elderly Patients: A Review of Epidemiology, Current Practices and Outcomes of Current Management Strategies. Can. J. Gastroenterol. Hepatol. 2015;29(6):327-33. https://doi.org/ 10.1155/2015/136960 PMid:26069892 PMCid:PMC4578457

13. Benchimol El, Fortinsky KJ, Gozdyra P, et al. Epidemiology of pediatric inflammatory bowel disease: A systematic review of international trends. Inflamm Bowel Dis. 2011;17(1):423-39. https://doi.org/10.1002/ibd.21349 PMid:20564651

14. Malmborg P, Grahnquist L, Lindholm J, Montgomery S, Hildebrand $H$. Increasing Incidence of Paediatric Inflammatory Bowel Disease in Northern Stockholm County, 2002-2007. J. Pediatr. Gastroenterol. Nutr. 2013;57(1):29-34. https://doi.org/10.1097/mpg.0b013e318 28f21b4 PMid:23459320

15. Cosnes J, Gower-Rousseau C, Seksik P, Cortot A. Epidemiology and natural history of inflammatory bowel diseases. Gastroenterology 2011;40(6):1785-94. https://doi .org/10.1053/j.gastro.2011.01.055 PMid:21530745

16. Molodecky NA, Soon IS, Rabi DM, et al. Increasing incidence and prevalence of the Inflammatory Bowel Diseases with Time, Based on Systematic Review. Gastroenterology 2012; 142(1):46-54.e42. https://doi.org/10.1053/j.gastro.2011.10. 001 PMid:22001864
17. Sands BE. From symptom to diagnosis: clinical distinctions among various forms of intestinal inflammation. Gastroenterology 2004;126(6):1518-32. https://doi.org/ 10.1053/j.gastro.2004.02.072 PMid:15168364

18. Jaffe TA, Gaca AM, Delaney S, Yoshizumi TT, Toncheva G, Nguyen G. Frush DP. Radiation doses from small-bowel follow-through and abdominopelvic MDCT in Crohn's disease. AJR Am. J. Roentgenol. 2007;189(5):1015-22. https://doi.org/10.2214/ajr.07.2427 PMid:17954634

19. Baumgart DC, Sandborn WJ. Crohn's disease. The Lancet 2012;380(9853):1590-605. https://doi.org/10.1016/s01406736(12)60026-9

20. Dos Santos CH, Da Silva Menezes JN, Nunes TF, De Assis Martins L. CT enterography in the evaluation of Crohn's disease. J. Coloproctol. 2015;35(4):217-22. https://doi.org/10.1016/j.jcol.2015.06.006

21. Paulsen SR, Huprich JE, Fletcher JG, et al. CT enterography as a diagnostic tool in evaluating small bowel disorders: Review of clinical experience with over 700 cases. RadioGraphics 2006;26(3):641-57. https://doi.org/10.1148/ rg.263055162 PMid:16702444

22. Choi D, Jin Lee S, Ah Cho Y, et al. Bowel wall thickening in patients with Crohn's disease: CT patterns and correlation with inflammatory activity. Clin. Radiol. 2003;58(1):68-74. https://doi.org/10.1053/crad.2002.1068 PMid:12565208

23. Hara AK, Swartz PG. CT enterography of Crohn's disease. Abdom. Imaging 2008;34(3):289-95. https://doi.org/ 10.1007/s00261-008-9443-1 PMid:18649092

24. Madureira AJ. The Comb Sign. Radiology 2004;230(3):783-4. https://doi.org/10.1148/radiol.2303020645 PMid:14990842

25. Hara AK, Alam S, Heigh RI, Gurudu SR, Hentz JG, Leighton JA. Using CT enterography to monitor Crohn's disease activity: A preliminary study. AJR Am. J. Roentgenol. 2008;190(6):1512-6. https://doi.org/10.2214/ajr.07.2877 PMid:18492900

26. Bodily KD, Fletcher JG, Solem CA, et al. Crohn disease: Mural attenuation and thickness at contrast-enhanced CT enterography-Correlation with endoscopic and histologic findings of inflammation. Radiology 2006;238(2):505-16. https://doi.org/10.1148/radiol.2382041159 PMid:16436815

27. Colombel JF, Solem CA, Sandborn WJ, et al. Quantitative measurement and visual assessment of ileal Crohn's disease activity by computed tomography enterography: correlation with endoscopic severity and $C$ reactive protein. Gut 2006;55(11):1561-7. https://doi.org/10.1136/ gut.2005.084301 PMid:16648154 PMCid:PMC1860143

28. Chiorean MV, Sandrasegaran K, Saxena R, Maglinte DD, Nakeeb A, Johnson CS. Correlation of CT enteroclysis with surgical pathology in Crohn's disease. Am. J. Gastroenterol. 2007;102(11):2541-50. https://doi.org/10.1111/j.1572-0241. 2007.01537.x PMid:17900329

29. Bruining DH, Siddiki HA, Fletcher JG, Tremaine WJ, Sandborn WJ, Loftus EV. Prevalence of penetrating disease and extraintestinal manifestations of Crohn's disease detected with CT enterography. Inflamm Bowel Dis. 2008;14(12):1701-6. https://doi.org/10.1002/ibd.20529 PMid:18623171

30. Stange EF. European evidence based consensus on the diagnosis and management of Crohn's disease: definitions and diagnosis. Gut 2006;55(suppl_1):i1-i15. https://doi.org/10.1136/gut.2005.081950a PMid:16481628 PMCid:PMC1859998 
31. Macari M, Megibow AJ, Balthazar EJ. A pattern approach to the abnormal small bowel: Observations at MDCT and CT enterography. AJR Am. J. Roentgenol. 2007;188(5):1344-55. https://doi.org/10.2214/ajr.06.0712 PMid:17449781

32. Patel B, Mottola J, Sahni VA, et al. MDCT assessment of ulcerative colitis: radiologic analysis with clinical, endoscopic, and pathologic correlation. Abdom. Imaging 2011;37(1):61-9. https://doi.org/10.1007/s00261-011-9741x PMid:21603899

33. Hashimoto S, Shimizu K, Shibata $H$, et al. Utility of computed tomographic enteroclysis/enterography for the assessment of mucosal healing in Crohn's disease. Gastroenterol Res Pract. 2013;2013:1-5. https://doi.org/ 10.1155/2013/984916 PMid:23710169 PMCid:PMC3655562
34. Park MJ, Lim JS. Computed tomography enterography for evaluation of inflammatory bowel disease. Clin. Endosc. 2013;46(4):327-66. https://doi.org/10.5946/ce.2013.46.4. 327 PMid:23964329 PMCid:PMC3746137

35. Peng JC, Feng Q, Zhu J, Shen J, Qiao YQ, Xu JR, Ran ZH. Usefulness of spectral computed tomography for evaluation of intestinal activity and severity in ileocolonic Crohn's disease. Therap Adv Gastroenterol. 2016;9(6):795805. https://doi.org/10.1177/1756283×16668309 PMid: 27803734 PMCid:PMC5076778

36. Lopes S, Andrade P, Afonso J, et al. Monitoring Crohn's disease activity: endoscopy, fecal markers and computed tomography enterography. Therap Adv Gastroenterol. 2018;11:1-12. https://doi.org/10.1177/1756284818769075 PMid:29760785 PMCid:PMC5946585 